\title{
«MITTO IN BAIOLIA». LES SOLIDARITATS FAMILIARS I FEUDALS A LA CATALUNYA MEDIEVAL (S. X-XII)
}

\section{Antoni Udina Abelló}

\section{INTRODUCCIÓ}

L'estudi del dret vigent als comtats catalans en el període altomedieval, és a dir fins a la recepció del dret comú, planteja un primer problema: el de les fonts. Ens trobem, en paraules de Lalinde, en un període de dispersí normativa que arrenca amb la supervivència de l'ordre dels gots i que durarà fins al segle $\mathrm{XII}^{1}$. la perduració del marc legal visigot a la Catalunya entre els segles IX I XII ha estat objecte de valoracions i d'estudis diversos que, en general, remarquen el seu vessant cultural ${ }^{2}$.

La feudalització de la societat catalana tindrà, però, conseqüències en determinades institucions de dret públic i privat. Nhi ha una que és ben evident en la institució de la tutela, si bé en un document pel qual $\mathrm{Ri}$ quildis i els seus fills venen unes terres a Bofill Guilmund se cita textualment el capítol de la llei visigoda on aquesta institució es regula - LEX IV-III- $4^{3}$ - La forta solidaritat entre la noblesa feudal influirà de forma definitiva amb la introducció d'una nova institució semblant a la tutela: es tracta de la batllia personal. Només Lalinde l'ha tractat de passada, en introduir l'estudi del batlle i el veguer amb la precisió i rigorositat que caracteritzen tots els seus treballs; així assenyala que entre tutela $\mathrm{i}$ batllia hi ha clares analogies: recau en menors o incapaços; però hi

'LALINDE, J., Iniciación histórica al derecho español, Barcelona, 1970, p. 79.

${ }^{2}$ KIENASI, W., «Das Fortleben des gotischen Rechtes in Sudfrankreich und Katalonien», Al. bum J. Balon, Brussel-les, 1968.

UDiš, F., aEl sedimento visigodo en la Cataluñ condalh, Rev. Archivos, Bibliotecas y Museos, LXXVII-2 (1974), pp. 565-581, i

ZimmermanN, M. aL'usage du droit wisigothique en Catalogne du IX au XII siècle. Approches d’une signification culturelle», Mélanges de la Casa de Velázquez, IX (1973), pp. 233-281, en són alguns exemples.

${ }^{3}$ ACA. C.p. R. Ber.1, 339 (1066 gener 9). 
ha una diferència essencial: en la batllia aquests menors o incapaços són «poseedores de una titularidad dominical o análoga que exija una actividad superior a la meramente adminstrativas ${ }^{4}$. I encara podríem afegir un altre element diferenciador entre tutela i batllia personal: aquesta darrera pot recaure també sobre majors d'edat capaços d'obrar, com és el cas de l'esposa viuda. A més, la batllia no es limita a l'àmbit familiar, ja que castells, esglésies i viles senceres també en sỏn objecte, si bẻ aquest aspecte cau fora de l'àmbit d'estudi que ens proposem tractar en aquestes planes. Lalinde sosté que aquestes relacions de protecció s'enforteixen amb vincles feudals i permeten demostrar el fenomen d'adaptació a les institucions de les noves necessitats creades. Ara bé, fins a quin punt es tracta d'adaptació o de creació de la batllia personal fruit de les transformacions socials que condueixen a la feudalització de la societat, mirarem d'esbrinar-ho al llarg d'aquest estudi. Com podrem demostrar, cal destacar que la batllia, en bona part, substituirà o farà les funcions de la tutela en la societat catalana dels segles XI i XII.

La importància de la família com a cèl-lula de protecció de la persona en els segles medievals farà que ben aviat trobem que entre les provisions fetes pels testadors hi figurin la designació de persones a les quals se'ls encomana la cura dels familiars i de llurs béns. Aquest treball pretén relacionar els mecanismes jurídics que s'utilitzen amb el context social en el qual es produeixen.

El tipus documental que recull fonamentalment les disposicions sobre la batllia personal dels parents és el testament. Ja ens en férem ressò en analitzar el tema de la successió testada en els segles x i xi . $^{5}$. Això ens limitarà força l'espectre social del nostre estudi ja que, sobretot des del segon terç del segle xi, l'atorgament de testaments esdevé gairebé privatiu dels nobles $i$ dels eclesiàstics ${ }^{6}$; però d'altra banda crec que és lícit pensar que sobretot eren els nobles (del comte als cavallers) i els eclesiastics (dels arquebisbes $\mathrm{i}$ bisbes als diaques) els qui empren la institució tutelar. Tenim notícies escadusseres de la batllia en convinences feudals, sentències judicials i d'altres documents a què més endavant ens referirem. dels més de vuit-cents testaments analitzats, en cent seixanta-dos hi ha disposicions referents a batllia. En alguns les persones tutelades i llurs béns i els tutors designats són diversos: a tall d'exemple podem destacar que el castlà Arnau Miró deixa els seus quatre fills mascles en batllia de quatre tutors especificant-ne els posats sota batllia i els responsables, o el cas de Gombau de Besora que deixa

${ }^{4}$ LALINDE, J., La jurisdicción real inferior en Cataluña, Barcelona, Ayuntamiento, 1966. pp. 58 iss.

'Udina, A., La successió testada a la Catalumya altomedieval, Barcelona, Fundacio Noguera, 1984, pp. 125-126. En aquest treball caldrà matisar algunes de les afirmacions fetes aleshores.

${ }^{6}$ D'un total de més de vuit-cents testaments només un $6 \%$ correspon a pagesos. 
la seva esposa en batllia dels bisbes de Vic i de Barcelona, com també de tres dels seus nebots?

Les primeres mencions de batllia que hem trobat en la nostra recerca corresponen al darrer terç del segle x. El 970 Borrell disposa en el seu testament: "et ipso chavallo cum filio meo et uxor mea in potestate de seniori meo..., , a banda de destacar la importància del cavall, citat davant dels parents més propers, i malgrat que no s'empra el terme batllia; 1'any 981 la vídua del testador anterior, Inguilrada, també en testament disposa: «et mitto Suniario in baiulacione de filio meo Miro et precor te, filii carissime, ut mercedem abeas de illow ${ }^{8}$. La institució de la batllia anirà augmentant, i així mentre en la primera meitat del segle $\mathrm{XI}$ en trobem vint mencions, en el període 1151-1175 n'hi ha quaranta.

La terminologia per determinar la protecció de persones i béns disposada en testament és relativament variada.

El terme més corrent és el de baulia i altres formes anàlogues deformades: baglia, bagolia, badlia. A vegades associat o no al terme baiulia apareixen el de potestate i el de garda o guarda: en tots els casos en què apareixen algun d'aquests dos darrers termes els tutors o responsables designats de la batllia són senyors feudals dels testadors que fan llur designació ${ }^{9}$. Un darrer terme menys emprat és el de tuicione ${ }^{10}$.

\section{QUI DISPOSA LA BATLLIA I SOBRE QUINES PERSONES RECAU?}

Sembla clar que la necessitat de recórrer a la institució de la batllia personal respon, en bona part, a la situació d'indefensió social i econòmica en què romanien l'esposa vídua i els fills menors d'edat. Aixi, en quasi la meitat dels documents estudiats els posats sota batllia són els parents més propers del testador: l'esposa i els seus fills, tant si es tracta de comtes, vescomtes o altres grans nobles, com si els qui ordenen les disposicions tutelars són cavallers i fins i tot pagesos. És clar, doncs, que una de les fi-

${ }^{7}$ ACB, Div, 1-2-1493 (1082-X1-24) el d'Arnau Miró. El testament de Gombau de Besora publicat a Catalunya Romànica, X, p. 414.

${ }^{8}$ Vegeu els dos testaments a UdinA, A., La successió testada a la Catalunya medieval, Barcelona, Fundació Noguera, 1984, docs. 15 (970-X-19) i 23 (981-X-29), respectivament.

${ }^{9}$ Alguns exemples en què apareix ein potestate...) ACV cal. 6 p. 380 (1166), ACV cal. 6 p. 383 (1170-V -18), aIn potestate et in baiulia ... A AlnseNT, A:, Diplomatari... doc, 16 (1061VII-7), ibídem, doc. 315 (1167-IX-20); UdinA, A , La successió ıesıada ... doc, 66(1006-I-13). El terme garda el trobem, entre altres casos, a ACV Liber dotationum, f. 52. (1141-IV-3); BARAUT, C.. Els documents,... doc, 1531 (1157-1-30) i doc. 1478 (1141-V-13).

En algun cas trobem tots tres termes: «in guarda et in batlia et in potestaten: BARAUT, C., Els documents... doc. 1550 (1160-IV-20).

${ }^{10}$ ACV cal. 6 p. 2495 (1185-I-7). BC perg. 9822 (1093-VII-25) i ACV Cart. Sta. Maria de lEstany, doc. 43 (1143-IX-8). 
nalitats de la batllia és precisament la protecció de la família i dels béns que se li deixen. En trenta casos trobem designats com a posats sota batllia conjuntament l'esposa i els fills. Així, el vescomte d'Urgell, Guillem, que encomana a Guifré, el seu senyor, l'esposa i la filla, o el comte de Besalú, Bernat Tallaferro, que designa tutor de l'esposa i dels fills menors el primogènit Guillem amb una finalitat prou explícita: «ut ille in suis vicibus sit illorum pater» ${ }^{11}$. Amb més frequència són els grans nobles, propietaris o feudataris de castells qui disposen tutor per a la dona i per als fills: Ermengol d'Oló deixa l'esposa i els fills al seu germà Guillem, el qual vuit anys després encomanara la seva familia a les catedrals de Vic i de Barcelona ${ }^{12}$. Bernat Ermengol, Donuci Bernat, Sendret Company. Folc Ramon o Ramon Guillem de Taus són uns altres testadors nobles que dicten en llurs testaments disposicions tendents a assegurar la batllia per a l'esposa i per als fills. En el primer cas es tracta d'un fill que encara ha de néixer ${ }^{13}$. Són, però, els integrants de la baixa noblesa, castlans i sobretot els cavallers, els qui més sovint es preocupen en llurs testaments de designar tutor per a l'esposa $i$ per als fills: representen gairebé la meitat dels casos en què els posats sota batllia són l'esposa $i$ el fill o fills conjuntament i que no detallem per no allargar-nos-hi massa. Malgrat la dificultat que representa sovint fixar la condició social del testador que disposa la batllia, creiem que podem parlar de dos casos en què les disposicions tutelars són fetes per camperols: el cas de Ramon, que encomana al seu germà les persones i els béns de l'esposa $\mathrm{i}$ dels fills, $\mathrm{i}$ de Jofre, que deixa la dona $\mathrm{i}$ els fills en batllia d'un tal Joan Gausbert, probablement un amic seu ${ }^{14}$. En ocasions és solament l'esposa la designada com a pupil-la, potser per la manca de fills o perquè aquests són ja majors d'edat: són els casos dels testadors Llopart, Guiu Riculf i Arnau Miro, tots cavallers ${ }^{15}$; en el darrer cas, però, tambè són objecte de designació de tutor els fills del testador, si bé és diferent que el designat per a l'esposa. També Gombau de Besora posa sota la protecció dels bisbes de Vic i de Barcelona i dels seus mateixos nebots la seva dona Aurúcia ${ }^{16}$. Finalment, en cinquanta-quatre documents la designació de batllia recau en els fills de forma exclusiva, i en la majoria de casos sense que la mare, esposa del testador, hi figuri com a tutora, i això creiem que obeeix a dues ra-

\footnotetext{
"Publicats respectivament per Udiva, A., La successio.... doc. 90 i MARcA, P. DE, Marce Hispanica, doc. 191

2 Udna, A., La successió, ..., doc. 129 i ACV cal. 9 Ep. II perg. 35 respectivament.

13 ACA, C.p. Ramon Berenguer I, 96; Miouel, F., Liber Feudorum Maior, doc, 431; ACB LA IV, doc. 104; ACA OR. St. Benet de Bages, p. 375; ACA C. p. Ramon Berenguer II, 27 i miret y Sans, J., doc. 151 respectivament.

${ }^{14}$ ACV cal. 6 perg. 1483 (1077-VIII-28) i BC perg. 3661 (1097-V-1).

15 ACA OR Sta. Cecilia, p. 45 (1038-IV-2), RiUs, J., El Cartulario de San Cugat del Vallés, doc, 637 i Baraut, C., Els documents de l'Arxiu Capitular de la Seu d'Urgell, doc, 974 (1081XII-14).

16 Publicat a Catalunya Romànica, X, p. 414.
} 
ons possibles: que sigui morta o bé que quan el testador moria i deixava un cònjuge supèrstit era normal que aquest continués amb la pàtria potestat $i$, per tant, que no es plantegés el problema de designació de tutor. Veurem. en estudiar la figura del tutor, qui són designats com a tals en aquests casos i les raons corresponents. Cal fer un esment especial dels casos en què el designat és un fill nasciturus i que lògicament necessita protecció jurídica de forma ineludible: a més del cas de Bernat Ermengol abas al-ludit, també trobem la dita designació feta per part d'Ermengol Llobató, que designa la seva germana com a tutora del fill que ha de néixer, en cas que la mare, esposa del testador, es casés, un cop mort Ermengol, aquesta batllia es fa extensiva als béns deixats a l'esposa. Un altre cas de designació del fill pòstum com a pupil és feta pel feudatari Gombau Gombau, el qual escull com a tutor del fill que ha de néixer el castlà d'un dels seus castells, $i$, finalment, un darrer exemple ens l'ofereix el cavaller Josbert en designar el seu senyor Ramon Gerard com a tutor de quatre fills, un dels quals encara ha de néixer ${ }^{17}$.

De forma excepcional trobem persones objecte de batllia que tenen relacions de parentiu altres que amb el testador, $\mathrm{i}$ en uns pocs casos fins $\mathrm{i}$ tot sense cap relació de parentiu, almenys explícita.

La qualificació de fidelis feta a alguna dona designada juntament amb fills del testador per aquest objecte de batllia ens fa pensar que es tracta d'amistançades de preveres ${ }^{18}$. És el cas d'Artau Josbert, canonge de Vic, que posa sota batllia dels seus oncles la «fidelis» Nevia i els seus hereus, i el cas del també canonge, en aquest cas d'Urgell, Guadall, que designa tutor Mir Oldric de les persones de la afidelis» Sicardis i del fill Arnau, i el del prevere Ramon Guifré que posa sota batllia de l'abat de Sant Cugat els fills, la fidel Guidenellis i els béns a ells deixats ${ }^{19}$.

La mare del testador és objecte de disposicions de batllia en cinc casos. L'ardiaca Seniofred la deixa juntament amb els nebots sota batllia del bisbe de Vic, Borrell; el cavaller Galíl'encomana juntament amb la seva dona al seu senyor Ponç; Pere Guillen, al comte Guillem Ramon juntament amb l'aiou que li llega; el prevere Artal Artal la deixa «in baiulia et defensione...» d'un altre prevere, i el noble Umbert Gerbert designa els marmessors del seu testament com a tutors de la seva mare i del seu fill juntament amb els bén $\mathrm{s}^{20}$.

Quatre testadors inclouen, com a posats sota batllia, germans: es tracta de Guisard de Lluçà, un canonge de Vic de nom Ramon, l'ardiaca de la Seu d'Urgell, Guillem, i el prevere Artal Artal ${ }^{21}$. També apareixen designats ob-

17 ACB LA III, doc. 170; Rius, J., El Cartulario ..., doc. 521 i ACV cal. 6 perg. 1103.

18 Vegeu UdINA, A., La successió...., pp. 93-94.

19 ACV cal. 6 perg. 1118: ACU LDEU 1, 413 i RuUs, J., CSC doe, 660.

20 Vegeu respectivarnent UdiNA, A., La successio.... doc. 90; BC perg. 8722; Baraut, C. Els documents.... doc. 84: BC perg. 9714: RIUS, J., CSC doc. 731.

${ }^{21}$ Udiva, A., La successió.... doc. 66; ACV cal. 9 Ep. II perg. 57; Baraut, C., Els documents..., doc. 901 i BC perg. 9714 
jecte de la batllia alguns nebots: en dos casos amb la clàusula que siguin preparats per al clergat ${ }^{22}$.

\section{LA FIGURA DEL RESPONSABLE DE LA BATLLIA}

El responsable de la batllia designat pel testador no rep mai un nom concret. Com ha posat de relleu Lalinde, el terme baiulus s'empra quan la institució es patrimonialitza $\mathrm{a}^{23} \mathrm{i}$ adquireix un caràcter político-econòmic. A efectes pràctics i sense oblidar el que hem dit més amunt respecte a la diferència entre batllia personal i tutela, designarem amb el terme tutor el responsable d'oferir la protecció, tret essencial de la batllia.

Apareixen nomenats tutors preferentment els membres de l'alta noblesa en virtut de senyors dels testadors; en ocasions es fa referència expressa a llur qualitat de senior: en vint casos; peró és clar que en d'altres, el fet de ser senyors del testador determina que siguin nomenats tutors.

Com a cas excepcional podem destacar tres casos en què el rei Alfons el Trobador és designat tutor: es tracta del testament d'Ermengol VII, comte d'Urgell, que posa el seu fill aín garda et in baiulia» de l'esmentat rei, del comte Pallars, bisbe d'Urgell, vescomte de Cardona i del gran senescal Guillem Ramon; un segon cas és el de Sicards, que posa sota potestat del monarca l'esposa, els fills i els béns, i també és el rei Alfons sota la protecció del qual Guillem d'Alcarràs posa els seus parents: pare, mare, esposa, fills i els seus homes ${ }^{24}$.

És, a més del cas en què explícitament consta que són senyors, el cas del nomenament de membres de l'alta noblesa i de la jerarquia eclesiàstica com ara comtes, vescomtes, bisbes i abats com a tutors.

Trobem nou tutors que són comtes; en una ocasió és designat pel testament d'un altre comte Guillem Ramon de Cerdanya ${ }^{25}$, que hi designa un dels seus fills, Bernat. Ramon Berenguer III és nomenat tutor dels béns deixats a Sant Pere de Vic per l'arquebisbe de Vic Berenguer Sunifred de Lluça ${ }^{26}$. El comte de Cerdanya-Besalú, Guifré, germà de l'abat-bisbe Oliba, deixa sota batllia del germà Ramon, els fills Bernat i Berenguer i el comtat de Berga ${ }^{27}$.

Un dels grans nobles, Bernat Ermengol, posa l'esposa i el fill nasciturus amb el castell de Fornells sota batllia de Ramon Berenguer $\mathrm{I}^{28}$. Folc Er-

${ }^{22}$ BARAUT, C., Els documents.... doc. 568 i ACV cal. 6 perg. 2166.

Altres mencions de nebots posats sota batllia a SERRA, J., Los señores.... p. 17 i BC perg. 9822. Un cas en què el pupil és nebot nét és el de Berenguer Bernat ACB LA III doc. 17.

${ }^{23}$ La jurisdicción... cit. p. 68 .

${ }^{24}$ Baraut, C., Els documents..., docs. 1621 i 1646. El tercer document esmentat publicat per Altisent, A., Diplomatari de Santa Maria de Pobler, doc. 571.

${ }^{25}$ MiQuel, F, Liber Feudorum..., doc. 694.

${ }^{26}$ AEV XIII perg. 20 (1099-1-28).

${ }^{27}$ MiQuel, F., Liber Feudorum..., doc, 693.

${ }^{28}$ MiQuEL, F., Liber Feudorum.... doc. 431. 
mengol, nét de Guillem de Mediona i senyor d’Oló, encomana els fills al comte de Barcelona ${ }^{29}$ : Amaltrud, vídua de Bofill Sanç, senyor de Llobera, deixa el fill i els béns - entre ells el castell de La Clusa- en batllia del comte Ermengol d'Urgell, a qui també se li confia la batllia dels fills i de l'esposa de Guillem Isarn ${ }^{30}$. Finalment són tres milites, un tal Maier, Pere Guillem i Gerbert ${ }^{31}$ qui designen tutors de familiars els comtes Ramon de Pallars, el ja citat comte de Cerdanya, Guillem Ramon, i els comtes de Barcelona, Ramon Berenguer 1 i Almodis, respectivament. En el cas dels cavallers Gerbert i Maier també hi figuren com a tutors Berenguer Mir i Ramon Seniofred, qualificats igual que els comtes de seniore.

Uns altres casos en què la designació de tutor obeeix a la relació feudal de vassallatge són els dels vescomtes: n' hi ha quatre casos. El cavaller Llopart posa sota batllia del vescomte de Cardona Fole I i també del bisbe Eriball, germà seu, la seva esposa i els béns a ella deixats ${ }^{32}$; Guitard Bernat deixa el fill i l'esposa «in potestate vel in baiulia...» del vescomte d'Urgell, Miró, i d'Arnau Dacó «ut bene baiuletis eis» ${ }^{33}$. Un tercer vescomte nomenat tutor és Guerau Ponç, vescomte d'Àger, a qui Galcerà Erimany, un gran feudatari, deixa les seus fills en batllia ${ }^{34} ;$ cal, però, destacar que en aquest testament es designen uns altres nobles com a tutors dels fills Pere i Galceran i dels castells a ells llegats. Un darrer exemple: el vescomte de Castellb6, el dia 26 de febrer de 1095, és designat tutor dels fills i béns del castlà Arnau Bernat per testament del mateix castla ${ }^{35}$. En tots quatre casos és la jurisdicció senyorial del vescomte la que determina la designació de tutor.

També les màximes jerarquies eclesiàstiques són designades amb funció tutelar: els bisbes de Barcelona, Vic i Urgell apareixen com a responsables de la batllia de familiars $\mathrm{i}$ béns de nobles laics i de canonges i preveres. A vegades es tracta de grans nobles com Guisad de Lluçà o Gombau de Besora, els quals disposen en testament la seva voluntat que el bisbe de Vic, Arnulf en el primer cas, i Oliba en el segon, siguin tutors dels fills, de l'esposa $\mathrm{i}$ del germà en el cas de Guisad ${ }^{36}$, i de la dona en el de Gombau, en què també se li encomana la batllia al bisbe de Barcelona ${ }^{37}$. El bisbe d'Urgell. Guillem, és designat tutor dels fills $\mathrm{i}$ dels alous llegats per Arnau Sal-la ${ }^{38} \mathrm{i}$

${ }^{29}$ ACA C. p. R. Berenguer II, 26 (1079-I-29).

${ }^{30}$ Baraut, C., Els documents.... doc. 1031 (1086-VIII-30), Serra.... p. 50.

${ }^{31} \mathrm{BC}$ perg. 3842 (1074-IX-2); BARAUT, C., Els documents .., doc. 842 i ACG (1069-I-13), respectivament.

${ }^{32}$ ACA OR Sta. Cecilia, perg. 45 (1038-IV-2).

${ }^{33}$ Baraut, C., Els documents..., doc, 745.

${ }^{34}$ BARAUT, C., Els documents.... doc. 1119 (1094-X-21).

${ }^{35}$ BARAUT, C., Els documents.... doc. 1127 (1095-II-26).

35 Udiva, A. La successió testada.... doc. 66. (1006-1-13).

${ }^{37}$ Publicat a Catalunya Romànica..., vol X, p. 414.

${ }^{38}$ Baraut, C., Els documents..., doc, 647 (1051-XI-14). 
de Tesposa $\mathrm{i}$ del fill Arnau per Goltret ${ }^{39}$. També el canonge Teobald posa sota batllia del bisbe de Vic tots els béns que deixa a diverses persones fisiques i jurídiques ${ }^{40}$.

Ja hem fet referència al bisbe Eriball com a tutor del miles Llopart abans. El bisbe Odó és designat tutor de la dona i dels fills de Vidià, i encara hi ha un altre bisbe d'Urgell, Bernat Guillem, a qui l'ardiaca Guillem fa tutor posant in baiulia l'honor que deixa al seu germà i que té en feu de l'església urgellesa $i$ del seu bisbe ${ }^{41}$; el dit bisbe Bernat Guillem rep la deixa del prevere Arnau referida al seu fill, que romandrà «in potestate Sancte Marie et eius episcopo ut sit nutritum ad clericatum.... ${ }^{22}$. El canonge Isarn, important senyor i propietari de terres de la zona, deixa en batllia del bisbe d'Urgell el seu fill Pere ${ }^{43}$, que encomana també als marmessors. Uns altres casos en què la batllia és atribuïda a bisbes són: el de l'ardiaca Seniofred, que posa sota batllia de Borrell, bisbe de Vic, la mare, els nebots i els homines depenents ${ }^{44}$; el també ardiaca de Vic, Sunyer, designa el bisbe Guillem com a tutor de la dona i dels fills juntament amb els béns llegats ${ }^{45}$, 1 encara dos casos més: Bofill Teobald en una clàusula al final del seu testament indica: whoc autem ut predictum est dimitto in proteccione et deffensione domni Berengarii archiepiscopi, seniori mei, et rogo bonitatem eius ut sit auditor et defensor..., mentre que el bisbe d'Urgell, Bernat, és designat tutor d'Arnau per disposició testamentària del seu pare Ramon ${ }^{46}$.

L'abat de Sant Cugat, com a senyor feudal, també rep la funció tutelar d'alguns testadors vinculats al monestir. Així, Ramon Guifré, un prevere, em sembla, li deixa els seus fills i una tal Gudunellis, qualificada de fidel, que seria l'amistançanda possiblement, «cum illorum propietate ${ }^{47}$. També, però, trobem cavallers que recorren a l'abat de Sant Cugat com a tutor: així, Guiu Riculf li encomana la batllia de l'esposa i dels alous i béns mobles a ella deixats, i Bardina, un altre miles, disposa que el seu fill Miró i els alous i feus deixats romanguin sota la batllia de l'abat i si el fill morís sense descendència que tots els béns deixats passessin a Sant Cugat ${ }^{48}$.

En d'altres ocasions, la funció tutelar és encomanada de forma genèrica a monestirs o catedrals. Aixf, in baiulia de Santa Maria de Girona, deixa Ar-

\footnotetext{
${ }^{39}$ BARAUT, C., Els documents .... doc. 742 (1062-XI-11).

${ }^{40} \mathrm{ACV}$ cal. 9 Ep. II p. 54 (1055-II-17).

${ }^{41}$ ALtisent, A., Diplomatari de Santa Maria de Poblet.... doc, 62 (1119-VIII-21) i BARAut, C., Els docienents.... doc. 901 (1076-1-23), respectivament.

${ }^{42}$ Baraut, C., Els documents.... doc. 938 (1080 V-11).

43 Baraut, C., Els documents.... doc. 1156 (1098-1-14).

${ }^{4}$ UdinA, A., La succcessió...., doc. 90 (1011-VII-25).

45 AEV XI, perg. 38 (1049-V-21).

${ }^{46}$ AEV XVI perg. 4 (1093-XI-28) i BARAuT, C., Els documents.... doc, 1550 (1160-IV-20).

${ }^{47}$ Rius, J., El Cartulario.... doc. 660 (1067-VII-31).

${ }^{48}$ Rrus, J., El Cartulario.... docs. 1053 (1063-VIII-3) i 793 (1058-I-28).
} 
nau Radulf, un cavaller, l'esposa i els fills per bé que s'especifiquen també com a tutors tres nobles més ${ }^{49}$. Vidal $\mathrm{i}$ els béns llegats per Guillem: la meitat d'un mas amb l'alou i unes vinyes són posats sota batllia de la catedral urgellenca $^{50}$. Finalment el ja citat feudatari de diversos castells, Galcera Erimany, deixa els seus fills en batllia de Sant Pere d'Àger i com ja s'ha dit dels vescomtes ${ }^{51}$. El prevere Ramon Guifré ordena que el seu fill Bernat romangui en batllia de Sant Cugat o Sant Llorenç del Munt i amb la condició explícita que se l'eduqui per a ser monjo ${ }^{52}$.

També els preveres són designats tutors. N'hem comptabilitzat quatre designats per d'altres prevers o diaques ${ }^{53}$. En quatre casos més, els testadors que designen com a tutors preveres són laics ${ }^{54}$.

La designació de tutors en la persona dels seus senyors és el criteri més utilitzat en els documents estudiats després del de la relació de parentiu.

A més de la qualificació com a senyors que es fa de tutors de què ja hem parlat, com ara comtes, vescomtes, abats, bisbes o preveres ${ }^{55}$, hem localitzat vint mencions explícites de senyors designats com a tutors pels testadors, als quals cal afegir-ne d'altres que pel context cal suposar-los com a tals. Així, per exemple, Guillem Bofill de Santa Coloma respecte a Hug Sendred, que li deixa en batllia l'esposa, els néts i els béns ${ }^{56}$, o Guillem Ramon de Castellvell respecte al miles Bernat Gerard, el qual li encomana el seu fill «cum alodis.... ${ }^{57}$. No volem allargar-nos massa amb la menció de tots els casos trobats. Ens limitarem a parlar d'alguns dels que ens semblen més significatius. Per la seva escassetat cal assenyalar de bell antuvi les úniques dues dones que com a domnae figuren designades per a la funció tutorial: es tracta de la ja citada Amaltrud, vídua de Bofill Sanç, a la qual Emma, amistançada del prevere Guifré, encomana la seva neboda Belisindis amb els béns mobles $i$ immobles que li llega, a més de deixar-li a la mateixa Amaltrud una euga i una capa ${ }^{58}$. L'altra domna nomenada tutora és Guisla, a qui Adroer

${ }^{49}$ ACG perg. 82 (1073-XII-28), Són Berenguer Rodball, Arnau Ramon i Ramon Speraendeu.

${ }^{30}$ Baraut, C.. Els documents.... doc, 1028 (1086-VI-28).

5) Vegeu nota 29.

52 Rius, J., El Cartulario.... doc. 640 (1064-V-21).

${ }^{53}$ BC perg, 9714 (1077-III-19); ACB LA II, doc. 272 (1077-XI-19) i Baraut, C., Els documents.... doc. 650 (1043-LX-30).

${ }^{54}$ Es tracta de Ramon, AES perg. 72 (1037-1-10), de Guitard Bernat: BARsuT, C. Els documents..., doc. 757 (1064-IV-9): Gombau Sanla, ACB LA IV, doc. 214 (1070-XI-17) i els esposos Bofill i Logridia, Baraut, C., Els documents.... doc. 650 (1052-VI-XI).

${ }^{55}$ Alguns casos a BC perg. 3842 (1074-IX-2); Ruus. J., El Cartulario .... doc. 611 (1058-I-28); ACA OR Bagà perg. 347 (1086-IV-15); B ARetr, C., Els documents..., doc. 1156 (1098-I-14).

${ }^{56}$ Publicat per Alturo, J., L'arxiu antic de Santa Anna del 942 al 1200. Barcelona, Fundací6 Noguera 1985, vol. II, doc. 130.

${ }^{57}$ ACB LA II doc, 409 (1097-VIII).

${ }^{58}$ SerRA, Los señores de Portell.... p. 17. 
deixa *in potestate et in patrocinion l'esposa i els fills ${ }^{59}$. Cal pensar també que en el segon cas es tracta d'una vídua.

També cal fer esment del cas en què la funció tutorial és compartida per dues persones qualificades de seniores: a més dels casos dels comtes abans al-ludits, assenyalem el del cavaller Berenguer Arnau, el qual disposa en el seu testament que l'esposa i els fills petits (infantes) romanguin ein baiolia domini Bernardi Berengarii et domini Bernardi de Olost cum illorum directis» i el d'Alamany Onofred, castlà d'Òdena, que posa l'esposa i els fills sota batllia de Guillem Ramon d'Òdena, Guillem Bernat i Guerau Alemany, tots qualificats en el testament de senyors ${ }^{60}$; podem pensar que pugui tractar-se de casos de vassallatge múltiple. Ens referim al fet, força freqüent en la segona meitat del segle XI, que els vassalls es comprometen amb més d'un senyor, la qual cosa motivarà l'aparició de la institució de l'home sòlid ${ }^{61}$.

A vegades el senyor feudal designat tutor comparteix aquesta atribució amb altres persones: és el cas de Berenguer Mir, designat com a tal juntament amb el comte de Pallars, Ramon ${ }^{62}$, el de Berenguer Guitart que comparteix amb Ramon Beltran la funció de batllia encomanada per Bernat Bernat respecte als seus fills ${ }^{63}$, i el cas de Ramon Berenguer d'Âger i Berenguer Mir d'Estopinyà, que són designats com a tutors juntament amb el vescomte Ponç Guerau, pel feudatari Galcerà Erimany dels fills i castells que figuren en el testament $t^{64}$. Uns altres senyors designats tutors figuren en els documents que citem en nota ${ }^{65}$.

També, per més que en casos més comptats, hi trobem la relació tutortestador contrària, en la qual el tutor designat és vassall de qui el nomena. Aixi, el castlà Dalmau Isarn figura com a tutor del fill pòstum de Gombau Gombau i de l'esposa i dels fills de Sendret Company ${ }^{66}$. En tots dos casos s'inclou el castell, del qual els testadors són senyors (eminents o feudataris).

Veiem també, en ocasions, la translació de la funció de tutor ordenada pel que fou designat originàriament: és, per exemple, el cas de la donació que el bisbe de Vic, Guillem, fa a Ramon Bofill uper baiuliam filii Tegballi» del qui es diu que és l'«avunculus», d'uns masos i d'unes terres a Gurb;

${ }^{59} \mathrm{ACV}$ cal. 6 perg. 1465 (1071-VI-16).

${ }^{60} \mathrm{ACV}$ cal. 6 perg. 1457 (1065-?-?) i ADM Conca leg. 6 núm, 276 (1085-III-25).

${ }^{61}$ Vegen Sal.rach, J.M., El procés de feudalització.... p. 338, i BonNassie, P., Catalunya mil anys..., II, pp. 190-193.

62 BC perg. 3842 (1074-IX-2).

${ }^{63}$ Rius, J., El Cartulario .... doc, 642 (1065-VII-27).

6. BARAT, J., Els documents..., doc, 1119 (1094-X-21).

os Borrell, aristòcrata vigatà, testament publicat per UDINA, A., La successió..... doc. 15; Gerivert i Sunyer, preveres, publicats per BaRAUT, C., Els documents..., doc. 568 i 660 ; Gali, BC perg. 8722; Arnau Bernat, BarauT, C., Els documents.... doc. 845; Bernat Ramon BC perg. 9873; Dalmau Arnau, BC perg. 9822; Ponç Oliba, BC perg. 9019.

${ }^{60}$ Ruus, J., El Cartulario..., doc. 709 (1083-II-2) i ACA OR St. Benet de Bages, perg. 357 (1078-XII-16) respectivament. 
es tracta sens dubte del canonge Teobald que, en testament dos mesos abans, havia disposat la batllia en mans del dit bisbe ${ }^{67}$.

El cas, però, més corrent és quan la designació de la funció tutorial recau en un parent del testador, que ho és lògicament també del pupil. En el primer apartat del treball ens hem referit als posats sota batllia i feiem esment que en la gran majoria de casos hi ha una relació de parentiu entre ells i el qui designa el tutor, ja que és fonamentalment la raó de ser de la institució que estudiem. Volem ara ací recollir i comentar alguns exemples que ens mostren quins familiars en concret són designats tutors. Encara que no gaire sovint, l'esposa del testador i mare dels seus fills n'és nomenada tutora en una venda que Ermetruit fa a Albaric d'unes terres que tenia per la batllia sobre el seu fill Guifré; aquesta notícia és una de les primeres referències a la institució tutelar que coneixem. També el noble Pere Miró designa la mare juntament amb l'esposa tutora dels seus fills ${ }^{68}$. Uns altres casos d'esposes designades tutores són el d'Aigane, la vídua del noble Bernat Gelmir que és tutora juntament amb el fill, primogènit suposem, Guerau, a condició que es comporti en la seva viudesa; un altre exemple el tenim en Berenguer Donuci quan designa tutora dels seus fills la seva esposa a qui llega tots els alous, que tindrà mentre visqui. En algun cas es tracta de la segona esposa la designada com a tutora dels fills de la primera, com fa en el seu testament Esteve Iotó, possiblement un pagès ${ }^{69}$. Uns darrers exemples ens demostren que no sempre l'esposa en ser designada tutora ho és respecte dels fills: així a la de Guiu Riculf, un cavaller del Vallès, se li encomana un tal Berenguer qualificat de nutricatum, i a Chixol, dona del castla Mir Llop Sanç, se li deixa in baiulia una tal Ermetruit, de la qual no consta el possible parentiu ${ }^{70}$.

\section{EL CONTINGUT DE LA BATLLIA}

Fonamentalment consisteix a cercar la protecció de l'esposa i dels fills: «remaneat in baiulia»; «dimitto in baiulia et in potestate...» que, com ja hem vist, s'encomana tant a parents com a senyors feudals laics i eclesiàstics, en pocs casos a comtes o a reis. La batllia, però, no recau solament sobre la persona, sinó que molt sovint hi són inclosos els béns deixats en el testament. La batllia personal i la real, doncs, sovint coincideixen. Les disposicions

\footnotetext{
${ }^{67}$ El primer document publicat per ORDEIG, R., Guillem Guifré de Balsareny, bisbe de Vic (Tesina de llicenciatura), Barcelona, 1981. El segon, ACV cal 9, ep. II p. 54 (1055-II-17).

${ }^{68}$ ACA OR St, Llorenç del Munt, perg. 26 (982-XII-13) i AltISENT, A., Diplomatari de Sta. Maria de Poblet..., doc. 16 (1061-VII-7) respectivament.

69 Vegeu respectivament ACB Dlv. 1-4-328 (1054-X); ACB Div, 1-1-1806 (1092-VIII-25) i ACA C. p. R. Berenguer II, 57 (1082-II-3).

${ }_{70}$ Rius, J., El Cartulario.... doc, 634 (1063-VI-29) i ACB, LA IV doc. 328 (1054-I-16).
} 
concretes, quan existeixen, es poden, doncs, referir a aspectes personals o/ $\mathrm{i}$ a aspectes patrimonials.

En el primer cas podern assenyalar una condició que trobem en alguns casos lligada a la batllia: la batllia sobre els fills es produirà si l'esposa del que l'ordena es casa, clàusula ben lògica car el nou matrimoni de la dona podria significar un abandó dels fills: són els casos de Trudgardis, que reb la batllia d'un fill postum del testador si l'esposa es torna a casar; semblantment els propinqui de Bofill Tedbald són designats tutors del seu fill Ramon si l'esposa del testador contrau nou matrimoni. En ocasions és la mateixa tutela de la mare, esposa del testador, la que es condiciona al fet de romandre vídua: Bernat Gelmir disposa que la seva esposa Aigane tingui la batllia dels fills esi digne in viduitate permansiset s?; també Guillem Guerau, que veu condicionada la seva funció de tutor al fet que l'esposa de Guitard Bernat es casi, segons ho disposa oralment ${ }^{72}$.

La referència a la cura de les necessitats materials com l'alimentació, el vestit o el calçat dels que són posats sota batllia és un altre dels aspectes que cal destacar i que en algunes ocasions figura explícitament citada en la disposició testamentària de la batllia: aixi, Dalmau Geribert, un destacat canonge de la Seu barcelonina, disposa en la batllia del seu nebot nét Berenguer Bernat que «ei tribuisset indumentum et calciamentum» i Bofill $\mathrm{Te}$ obald, un noble vigatà, disposa també per al seu fill «tribuat victum et indumentums ${ }^{73}$. També l'educació és objecte d'atenció en les disposicions tutelars: el fill de l'esmentat Guitard Bernat, Ramon, si la seva mare es torna a casar serà instruït per al clergat. Aquesta mena de disposicions és relativament frequient quan es disposa la batllia de menors; podem assenyalar respecte d'això diversos casos entre els quals destacarem el d'Arnau, fill d'Arnau Francó, deixat en batllia del bisbe d'Urgell «ut sit nutritum ad clericatum...», i el d'un altre Arnau, fill de Bernat d'Esplugues, que encomana la batllia al prevere de Santa Maria d'Esplugues amb condició igual ${ }^{74}$. Berenguer de Montcada posa sota potestat de Santa Maria de l'Estany el seu fill Guillem: «tali modo ut habeat ibi victum atque vestitum sicut unum canonicus honorifice dum vixerit, et si voluerit ibi vivere sub regula Sancti Augustini licitum sit ei» ${ }^{75}$. En d'altres casos la referència és més genèrica $i$ es pot referir també als aspectes materials assenyalats més amunt: el cas de

${ }^{71}$ ACB LA-III doc. 170 (1076-X-30): AEV, XVI-4 (1093-XI-28) i ACB p. 1-4-328 (1054-X). respectivament.

72 ACU LDEU I-432, publ. per BARAUT, C., Els documents,.., doc. 757.

73 Vegeu els documents respectius a ACB LA-III doc. 17 (1082-VIII-17) i AEV XVI-4 (1093-XI-28). Altres casos semblants a CSC ed. RIus, doc, 640 (1064-V-21) i ACV cal. 6 p. 2492 (1185-VII-19),

74 ACU p. 601 publ, per BARAUT, C.. Els documents..., doc. 481 (1080-V-11) i CSC ed. Ruus, doc. 1081 (1172-V-25) respectivament. Altres casos iguals a ACV cal. 6 p. 2166 (1059. VI-20): ACB LA-II, doc. 272 (1077-XI-9) i ACV cal. 6 p. 1103 (1095-IV-9).

75 ACA C.p. R. Berenguer IV, perg. 29 
Joan, fillol de Mir Queruci, el qual disposa en testament que Mir Guillem i Mir Goltred efaciant eum erudire litteris et tribuant ei omnia illi necesse fuerit...s $s^{76}$.

Tot plegat és una bona mostra de la voluntat d'assegurar el futur dels fills o dels nebots tot aprofitant la institució de la batllia.

En alguns casos, en fer l'encomanació de la batllia hi ha una sèrie de consideracions especials en raó, sens dubte, de la persona designada; és el cas del rei Alfons $i$ al qual Guillem d'Alcarràs li encomana la batllia de la seva família i dels seus homes: «dimitto in Dei fide et defensiore regis Aragonesis patrem meum et matrem et uxorem meam et filiam et milites meos et familiam, et rogo eum ut dominum karum in quo plurimum confido quatinus curam et studium prebeat qualiter debita que per eum debeo liberet et solvat, si ei placet, et amorem quem mihi per gratiam suam semper exhibuit, in hac ultima necessitate michi demonstret, quia ego semper habui cor meum in eo serviendo et honorandow? 77 . Aquí, a més de les consideracions personals de confiança i d'amistat envers el rei, hi ha l'encàrrec especific de vetllar pels familiars citats.

Hi ha també d'altres disposicions que refermen el caràcter feudal de la batllia: així, Guillem Amat designa tutor Ramon Gausbert de la forma següent: «precor Raimundum Gauzberti per Deum et sanctos eius sicut nihi promisit ita sit memor filiorum meorum sicut bonus ac nobilis homo debet facere per fidem rectam sine engan ${ }^{78}$; les darreres paraules, com és ben sabut, són les que figuren correntment en els juraments de fidelitat de l'època. Guillem de Lluçà deixa Ponç de Balsareny en batllia de la seva germana Ramona $i$ el seu nebot, $i$ ordena que el facin cavaller ${ }^{79}$.

Encara que no sempre es reculli de forma explícita, la batllia personal significava, en la nostra opinió, també la batllia real o patrimonial: primer perquè sovint hi ha una especial referència que els posats sota batllia siguin alimentats, vestits o educats, la qual cosa ens fa pensar en una compensació econòmica derivada dels béns deixats en testament, i, en segon lloc, perquè en alguns casos hi ha la referència explícita que la batllia comprèn també els béns. En ocasions es fa referència a tots els bén ${ }^{80}$; en d'altres és el castell o més exactament el castrum el que roman, juntament amb les persones, sota batllia del designat: així, Guillem de Mediona en disposar la

${ }^{76}$ Vegeu la publicació sagramental del testament a ACB LA II doc. 413 (1056-V-23).

77 Vegeu el document publicat per ALTISENT, Diplomatari.... doc. 57 .

${ }^{78}$ ACA OR St Llorenç del Munt, p. 262 (1127).

$79 \mathrm{ACV}$ cal. 6 p. 383 (1170-V-18).

80 eomnem meum averes, UdiNa, A, La successió testada..., doc. 122 (1022-VI-1); «cum illorum propietate* CSC, ed. Rus, doc. 660 (1067-VIII-31); ahec omnias BC p. 9845 (1071IX-22); ecum illorum honores, AltuRo, J., L'arxiu antic de Santa Anna..., doc, 130 (1092. VIII-28). Alguns altres casos en què sinclouen tots els béns, a ALTISENT, A. Diplomatari de Santa Maria de Poblet..., docs. 358, 441, 526. 
batllia de la seva dona i dels fills inclou el castell de Mediona; Sendret Company designa el castlà Dalmau Isarn com a tutor de l'esposa i del fill incloent-hi el castell de Guàrdia. Un tercer exemple és el castell de Fornells, posat, juntament amb l'esposa $i$ un fill postum del testador, sota batllia del comte Ramon Berenguer I per disposició de Bernat Ermengol ${ }^{81}$. En altres casos la batllia, a més dels parents del testador, comprèn els alous ${ }^{82} \mathrm{o}$ específicament els béns mobles ${ }^{83}$.

\section{CONCLUSIONS}

És clar que en la societat feudal catalana dels segles XI i xII coexisteixen dues formes de protecció de persones i dels seus béns que són la tutela i la batllia, si bé aquesta darrera pren una importància més gran perquè no es refereix tant als jurídicament incapaços d'obrar, sinó més aviat als qui necessiten protecció per la circumstància personal en la qual es troben: vídues i fills, no necesàriament menors d'edat, de nobles feudals. Això explica que les persones que reben l'encàrrec de la batllia siguin, a més dels familiars més directes (germans i oncles), personatges rellevants dins de la societat, tant laics com eclesiàstics.

La forma de designació de les dites persones és gairebé sempre per testament. El component religiós present en tota activitat humana en aquesta època fa que sovint la batllia sigui encomanada genèricament a una catedral, a un monestir o a una església, i específicament al seu bisbe, abat o prevere.

La clàusula més corrent fa referència a la batllia personal, a la qual s'afegeix sovint la patrimonial. Només excepcionalment, com ja s'ha recollit en el text, trobem disposicions concretes sobre l'educació, l'alimentació o la dedicació al clergat dels posats sota batllia.

Les escassíssimes referències a persones posades sota batllia no integrades en la noblesa feudal laica obeeix, al nostre parer, a dues raons fonamentals. D'una banda al fet que la tutela entre els no nobles seguiria la forma natural de designació, la del parentiu directe, sense que necessàriament s'hagués de recórrer al testament, i, en segon lloc, a la necessitat que tenien els vassalls nobles, entesos en un sentit ben ampli, d'assegurar el futur de l'esposa, dels fills i de llurs béns. Tot plegat és una prova més de la pèrdua d'importància de la tutela regulada en el dret visigot i l'aparició i consolidació d'aquesta nova institució que hem estudiat: la batllia, que substitueix gra-

${ }^{81}$ Vegeu ACV Ep. II-35 (1031-X-22) i AM Sant Benet de Bages, perg. 357 (1078-XII-16). MIOUEL. F., Liber Feudorum.... doc. 431 (1048-V-31), respectivament.

${ }^{82}$ Baraut, C., Els documenis.... docs. 603, 647, 842. ACB Div. 1-1-1806 (1092-VIII-25); CSC ed. Rius, docs. 634,637 i 640.

${ }^{83}$ BARAuT, C., Els documents..., doc. 654 (1052-VII-21); CSC ed. RuUs, doc, 637 (1063VIII-3). 
dualment la tutela. 1 això originat per les noves circumstàncies socials $\mathrm{i}$ econòmiques nascudes amb la feudalització de la societat. La batllia, doncs, respon perfectament a les necessàries solidaritats que enfortien i preservaven el paper rector de la noblesa feudal en la societat catalana dels segles XI i xII.

\section{ABREVIATURES EMPRADES EN LES NOTES}

$\mathrm{ACA}=$ Arxiu de la Corona d'Aragó

$\mathrm{ACB}=$ Arxiu Capitular de Barcelona

$\mathrm{ACG}=$ Arxiu Capitular de Girona

$\mathrm{ACU}=$ Arxiu Capitular de la Seu d'Urgell

$\mathrm{ACV}=$ Arxiu Capitular de Vic

AES $=$ Arxiu Episcopal de Solsona

$\mathrm{BC}=$ Biblioteca de Catalunya

$\mathrm{p}=$ pergamins

cal. $=$ calaix

\section{FONTS DOCUMENTALS PUBLICADES UTILITZADES}

ALtisEnt, A., Diplomatari de Sta. Maria de Poblet, vol, i, Barcelona, Generalitat de Catalunya, 1993.

Alturo, J., L'arxiu antic de Santa Anna de Barcelona del 942 al 1200, 3 vols., Barcelona, Fundació Noguera, 1986.

BARAUT, C.., «Els documents de la catedral d'Urgell. s. IX-XIl», Urgellia II-IX.

MarCA, P. de, Marca Hispanica, Barcelona, 1972 (fotom. ed. 1688 de París).

Miquet, F., Liber Feudorum Maior, 2 vols., Barcelona, CSIC, 1948.

Rius, J., El Cartulario de Sant Cugat, 3 vols., Barcelona, CSIC, 1945-47.

UdinA, A., La successió testada a la Catalunya altomedieval, Barcelona, Fundació Noguera, 1984. 